\title{
Artigos
}

\section{Repensando as políticas de Saúde no Brasil: Educação Permanente em Saúde centrada no encontro e no saber da experiência*}

\section{Rethinking Health policies in Brazil: Continuing Education in Health focused on meeting and knowing from experience(abstract: p. 12)}

\section{Repensando las politicas de Salud en Brasil: Educación Permanente in Salud enfocada en el encontro y el saber de la experiencia (resumen: p. 12)}

\author{
Monica Sampaio de Carvalho(a) \\ $<$ monicarvalho19@gmail.com> \\ Emerson Elias Merhy ${ }^{(b)}$ \\ <emerhy@gmail.com.br>
}

Maria Fátima de Sousa(c)

<mariafatimasousa@uol.com.br>

\author{
Este artigo é resultado da tese de \\ doutorado intitulada "Educação \\ Permanente enquanto lugar do \\ encontro: o que vê, o que se diz do \\ que se vê e o que se faz e se aprende \\ com o saber da experiência" \\ (a) Pós-Graduação em Saúde Coletiva \\ (Doutorado), Faculdade de Ciências \\ da Saúde, Universidade de Brasília \\ (UnB). Campus Universitário Darcy \\ Ribeiro, s/no, Asa Norte. Brasília, DF, \\ Brasil. 70910-900. \\ (b) Curso de Medicina, Universidade \\ Federal do Rio de Janeiro. Macaé, \\ RJ, Brasil. \\ (c) Departamento de Saúde Coletiva, \\ Faculdade de Ciências da Saúde \\ UnB. Brasília, DF, Brasil.
}

Este artigo tem o objetivo de discutir a formação em Educação Permanente em Saúde (EPS) denominada "EPS em Movimento" e realizada em 2012 pelo Departamento de Gestão da Educação na Saúde (DEGES) da Secretaria de Gestão do Trabalho e da Educação na Saúde (SGTES) do Ministério da Saúde (MS) do Brasil, em parceria com instituições de ensino, trabalhadores e gestores do Sistema Único de Saúde (SUS), e que teve como aposta principal dar visibilidade às experiências de EPS, provenientes das afecções e dos encontros. Pretende-se cartografar e compreender essa experiência, seu caráter inovador e a conexão com os modos como as políticas de saúde para o SUS estão sendo formuladas e implementadas, incluindo a Política de Educação Permanente em Saúde instituída no Brasil desde 2003.

Palavras-chave: Políticas de saúde. Educação permanente. Encontro. 


\section{Introdução}

As políticas públicas, além de incluírem ações de governo para enfrentamento de problemas da coletividade, envolvem interesses de múltiplos atores que disputam cotidianamente ideias, valores, visão de mundo e narrativas, vetores que influenciam e definem o desenrolar dessas políticas nos territórios.

Em geral, o modo instituído de formulação das políticas de saúde no SUS passa por uma formulação mais centralizada, sendo, em sua grande maioria, o Ministério da Saúde o principal protagonista dessa formulação, que, em geral, utiliza mecanismos de indução, na sua maior parte de cunho financeiro, para fomentar práticas e padróes que se desejam alcançar. O fomento à construção dessas políticas indutoras foi intensificado sobretudo na década de 1990, com a aprovação da Norma Operacional Básica (NOB) $96^{1(\mathrm{~d})}$, condicionando a habilitação dos entes municipais e estaduais, em modalidades de gestão, a incentivos financeiros, como o Piso de Atenção Básica (PAB) fixo e variável; incentivos de média e alta complexidade (MAC) articulados à produção; incentivos da Vigilância à Saúde, entre outros.

Embora alguns avanços oriundos desses mecanismos de indução tenham acontecido, como a definição de um piso para as açôes de Atenção Básica, o que se pretende ressaltar aqui é o distanciamento e a dicotomia entre a formulação e a execução dessas políticas de saúde; e o engessamento e rigor dos padróes exigidos, sem olhar a diversidade e necessidades das regióes, produzindo, assim, dificuldades na gestão das políticas, baixo protagonismo dos gestores municipais e estaduais e demais atores nos territórios e a insatisfação dos usuários do sistema.

Esses campos de tensão e de disputas trazem para a cena algo que escapa do controle almejado pela gestão, quando observamos gestores, trabalhadores do SUS e até mesmo usuários inventando novas formas de resolver os problemas do cotidiano que podem passar ou não alheias às políticas formuladas. Foucault ${ }^{2,3}$ já discutia essa questão em seus estudos sobre biopoder e governamentalidade ${ }^{(e)}$; e Deleuze e Guatarri ${ }^{4}$ no âmbito da subjetividade - compreendendo esta não como algo individual, do sujeito, mas como múltiplos vetores sociais, econômicos, físicos, técnicos, políticos e existenciais a partir dos quais pode emergir um território existencial.

Alguns autores, no campo da saúde coletiva no Brasil, como Merhy ${ }^{5}$ e Feuerwecker ${ }^{6}$, abordam esse tema da micropolítica em seus estudos para discutir o trabalho em saúde e os modos de governar as políticas de saúde. Entende-se aqui micropolítica não como algo menor, mas, como pensa Guatarri et al. ${ }^{7}$, como aquilo que acontece no âmbito das relações e dos desejos e que não se polariza com a macropolítica, uma vez que existe micropolítica nas relaçóes de macropoder, assim como a micropolítica pode emanar acontecimentos que ganham visibilidade na macropolítica.

Utilizando esses conceitos - ferramenta dos autores -, pretende-se cartografar a EPS e a mais recente proposta de formação EPS em Movimento, por meio de seus enunciados ou experiências nos territórios, como nos propóe Rolnik ${ }^{8}$, a "dar língua aos afetos e construir pontes de linguagem para travessia em outros territórios cartográficos” (p. 23) de maneira a produzir a seguinte reflexão: é possível pensar em novos modos de construir políticas de saúde e de formação? O que a experiência da EPS, sobretudo a EPS em Movimento, tem a nos dizer sobre essa questão? (d) NOB elaborada pelos gestores de forma tripartite para ordenar a organização do SUS.

(e) Governamentalidade é a "maneira como se conduz a conduta dos homens" ou "uma proposta de grade de análise para as relações de poder". 


\section{A Política de Educação Permanente: um breve histórico}

Os primeiros relatos sobre Educação Permanente (EP) remontam à década de 1930 com o pensamento de Pierre Furter ${ }^{9}$ por meio de críticas à educação tradicional, e que influenciou, na década de 1960, os documentos da Organização das Naçôes Unidas para Educação, Ciência e Cultura (Unesco) ${ }^{10}$ sobre o tema educação para adultos. Feuerwerker', em sua tese de livre docência "Micropolítica e Saúde: produção do cuidado, gestão e formação", detalha esse histórico e a sua conexão com as ideias de pensadores brasileiros como Paulo Freire ${ }^{11}$, Darcy Ribeiro ${ }^{12}$ e Florestan Fernandes ${ }^{13}$.

$\mathrm{Na}$ década de 1980, a Opas ${ }^{14}$ recomenda a estratégia de EPS para os países da América Latina no momento em que se discutia a baixa efetividade de estratégias tradicionais de educação, por meio de treinamentos e capacitações ofertadas para a rede de saúde. O movimento da Reforma Sanitária e as várias recomendações das Conferências de Saúde também apontavam para a necessidade de se olhar para essa questão ${ }^{15}$. A proposta tinha como objetivo não apenas ser uma forma de superar carências de formação dos trabalhadores, mas também ser uma estratégia para integrar o ensino no campo da saúde.

Em 2003, com a expansão da Estratégia Saúde da Família e a necessidade de se estruturar melhor a gestão do trabalho e a educação, surge a SGTES como uma secretaria voltada para propor políticas públicas voltadas para o trabalho e educação na saúde.

Uma das apostas da nova secretaria foi a implantação da Política de EP para o SUS, que passou por amplo debate com os diversos segmentos da gestão, trabalhadores e Conselho Nacional de Saúde. A Resolução CNS nº 335/2003 $3^{16}$ reconhece a EP como uma política pública do SUS e, em 13 de fevereiro de 2004, é publicada a Portaria no 198/GM/MS9 após aprovação em Comissão Intergestores Tripartite (CIT) ${ }^{17}$.

A EPS passa então a fazer parte da agenda de governo. O maior desafio era mobilizar o conjunto de atores do SUS para uma visão reflexiva do trabalho em saúde, não apenas como um lugar que recebe as políticas, mas como um lugar de produção de políticas.

Foram assim implementados os Polos de Educação Permanente em Saúde como espaços de mobilização desses atores do SUS e das instituições de ensino, na perspectiva do quadrilátero ${ }^{18}$, figura geométrica utilizada para representar a composição dos polos, remetendo-se aos atores - população; trabalhadores e gestores do SUS; e aparelho formador - que precisavam estar juntos nos processos de construção da política, no mapeamento de necessidades, na definição de prioridades e na gestão da política.

Os Polos de Educação Permanente em Saúde para o SUS são instâncias interinstitucionais e locorregionais/rodas de gestão com o objetivo de elaborar projetos de: mudança na educação técnica, na graduação, nas especializações em serviço, nas residências médicas ou outras estratégias de pós-graduação; desenvolvimento dos trabalhadores e dos gestores de saúde; envolvimento com o movimento estudantil da saúde; produção de conhecimento para a mudança das práticas de saúde e de formação, bem como a educação popular para a gestão social das políticas públicas de saúde ${ }^{17}$.

A política apostou nesse protagonismo e criatividade local para definir os arranjos possíveis no território. A agenda participativa é evidenciada com a participação efetiva dos diversos segmentos do SUS e da Educação, na construção cotidiana da política, a 
partir das necessidades locorregionais, visando à transformação e ao fortalecimento do sistema de Saúde.

A noção de gestão colegiada, como nas rodas dos jogos infantis, coloca a todos como participantes de uma operação conjunta em que todos usufruem o protagonismo e a produção coletiva. Por isso, a União e os Estados têm de problematizar para si a função e o exercício de uma coordenação com capacidade descentralizadora, e os municípios e as escolas terão de problematizar para si as funções de condução e de execução significativas para o Sistema, e não para a produtividade educacional e assistencial, respectivamente. Enquanto os últimos são os lugares de produção da atenção aos grupos sociais territorializados, os anteriores são os apoiadores de ativação para que esta atenção seja integral e resolutiva ${ }^{17}$.

A proposta de formação de Facilitadores de EPS e a de Ativadores de Processos de Mudança (APRENDER SUS) ${ }^{19,20}$; sendo a primeira mais voltada para os serviços de saúde e gestão do SUS e a segunda, mais voltada para formação, residência e graduação; foram responsáveis por intensa mobilização locorregionais e construção coletiva da política por meio de um processo de formação participativo, problematizador e construtivista. Muito mais que um conceito pedagógico ou metodológico, a EPS se propôs a ser um processo de desacomodação e de questionamentos que buscam transformar a realidade, como afirmam Ceccim e Ferla ${ }^{21}$.

Em junho de 2005, com a mudança do MS, uma nova gestão assume a SGTES, modificando os rumos da política e estabelecendo outras agendas prioritárias. Não pretendendo fazer uma análise dessas novas agendas que surgiram para o SUS, entre elas, as diretamente relacionadas ao ensino de graduação e pós-graduação - como o Programa Nacional de Formação Profissional em Saúde (Pró-Saúde) e o Programa de Educação pelo Trabalho para a Saúde (PET-Saúde), entre outros -, o que se observou, em relação à EPS, foi uma desmobilização dos atores, gerando uma lacuna nesse âmbito de política de educação para os trabalhadores do SUS.

Em pesquisa realizada pela Escola de Enfermagem da Universidade de São Paulo de Ribeirão Preto, por meio do Programa Especial de Cooperação com o Ministério da Saúde, Edital MCT/CNPQ/MS-SCTIE-DECIT no 23/2006, intitulada "Avaliação das Experiências de Educação Permanente em Saúde desencadeadas a partir da formação a distância de tutores e facilitadores em todas as regióes do Brasil”22, o relatório trouxe a percepção de como a política acontecia em alguns municípios de estados como São Paulo, Minas Gerais, Espírito Santo, Paraná, Santa Catarina, Mato Grosso do Sul, Paraíba e Bahia.

O estudo mostrou o quanto a EP é uma proposta contra-hegemônica e que, embora haja movimentos diversos para enfraquecê-la, ela resiste. Os modos de resistência são evidenciados na micropolítica, como veremos mais evidentemente na experiência EPS em Movimento, apesar de boa parte dos governos estaduais, municipais ou federais não tomarem essa agenda como estratégica e estruturante para o SUS, como revela o estudo. Além disso, a pesquisa avaliou que a estratégia dos facilitadores em EPSE, em curto espaço de tempo, não conseguiu ganhar a capilaridade necessária no território, devido aos aspectos relacionados à governabilidade desses 
atores na ação política e múltiplas visões de EP em disputa no território, algumas mais voltadas para a dimensão pedagógica, discutindo o processo de trabalho por meio de estruturação de linhas temáticas já previamente definidas pela gestão; outras, em menor escala, atuando de forma mais intuitiva e possibilitando um maior protagonismo dos trabalhadores nesse processo.

Em 2007, nova portaria é publicada: a Portaria GM/MS no $1.996 / 2007^{23}$, propondo revisão da política. Criam-se as Comissões Permanentes de Integração Ensino-Serviço (CIES), instâncias intersetoriais e interinstitucionais permanentes que participam da formulação, condução e desenvolvimento da política de EPS e estabelecem mecanismos de repasse fundo a fundo de recursos para a política, articulados a planos estaduais e regionais de EP.

Algumas dificuldades na implantação das CIES foram evidenciadas, como o distanciamento dessas instâncias das realidades locais; a baixa representatividade dos diversos segmentos do SUS; precária governabilidade, sobretudo dos entes executores da política (municípios) em relação aos recursos disponíveis de EP sob gestão estadual; e a não priorização do tema por parte das instâncias de gestão do SUS - Comissão Intergestores Bipartite (CIB) e Comissão Intergestores Regional (CIR) -, as quais as CIES estão vinculadas. Além disso, os planos de educação permanente se constituíram mais como uma agenda burocrática para cumprir os pré-requisitos exigidos pela indução financeira, com ações centradas apenas em cursos, muitas vezes elaborados de forma desarticulada com a realidade local.

Concordando com Cavalcanti ${ }^{24}$, essas medidas no âmbito macropolítico não conseguiram retomar a agenda da EPS com a potência a qual ela se propunha, desmobilizando os polos e, consequentemente, os atores envolvidos com a pauta da educação permanente na saúde, sobretudo nos municípios. Em resumo e corroborando o que propõe o artigo, observam-se, no transcorrer da implantação da política, movimentos macro e micropolíticos que emergem, gerando deslocamentos e alteraçôes nos fluxos dos acontecimentos, podendo produzir aumento ou perda de potência de uma determinada política.

\section{A Educação Permanente em Saúde em Movimento}

Em 2012, o DEGES/SGTES/MS propõe, em parceria com instituições de ensino, gestores e trabalhadores do SUS, a EPS em Movimento, que conseguiu produzir uma experiência nacional de formação semipresencial em EPS, que tem registro em Plataforma Virtual e que contou com o envolvimento de cerca de seis mil alunos, seiscentos tutores e sessenta apoiadores; entre eles, gestores, docentes, trabalhadores e estudantes das diversas esferas do SUS das várias regióes do país ${ }^{25}$. Não foi adiante por conta de outras prioridades governamentais e, sobretudo, por decorrência das mudanças nos rumos do país.

Diferentemente dos processos formais de formação, a proposta EPS em Movimento se propôs a ser um dispositivo, no sentido do pensamento foucaultiano, como "linhas de visibilidade e de enunciação ou ainda linhas de força e de subjetivação, que se entrecruzam e se misturam"26 (p. 155) para trazer o instituinte ${ }^{(f)}$ e, assim, explorar a potência dos encontros no mundo do trabalho a partir da EPS que acontece em si e no cotidiano dos serviços de saúde. (f) Instituinte são linhas de força de processos de mudança. É o novo, o inusitado. 
Spinoza já fala em sua produção sobre a potência dos encontros, alegres e tristes, que intensificam ou reduzem a potência do viver ${ }^{27}$.

São por meio desses encontros, nos quais os regimes de verdade ${ }^{(\mathrm{g})}$ discursivos e não discursivos se apresentam e, que o que se vê e o que não se vê; o que se diz e que não se diz; e o que se faz com tudo isso se revelam, produzindo afecçóes, deslocamentos e aprendizagem.

A EP constitutiva de aprendizado no trabalho e nos modos de existir no mundo nos convida a olhar diferente, para além do que está estabelecido, mesmo na repetição dos atos em saúde. É a partir da observação, dos desejos e das afecçôes dos encontros que a Educação Permanente acontece. Afecções no sentido ${ }^{28,29}$ que Spinoza nos traz como "tudo aquilo que nos afeta, por meio dos encontros, alegres ou tristes, e produz alteraçóes no nosso corpo, podendo produzir um desconforto, uma reflexão, um sentimento, uma ação, um aprendizado, responsável por aumentar ou diminuir a potência de vida”(h).

A proposta de formação EPS em Movimento teve como objetivo não seguir a modularidade e linearidade comuns nos processos formativos de ensino a distância (EAD), nos quais os alunos vão vencendo as etapas do conhecimento por meio de unidades de aprendizagem. Na EPS em Movimento, quem faz o percurso formativo é o aluno, a partir de suas afecções no território, com o apoio do tutor que oferta ferramentas a partir de sua experiência e o provoca a ir ao encontro de suas experiências de EP. O material, em constante construção, propóe-se a ser uma caixa de ferramentas que o participante faz uso de acordo com as suas necessidades e desafios do cotidiano, podendo ainda deixar suas contribuiçóes autorais, por meio do que foi denominado diário cartográfico e/ou caixa de afecçôes.

Muito mais que um registro de atividades, o diário cartográfico constituiu-se em um espaço de criação, com abertura para a inventividade, para produção de narrativas e de conhecimento, oriundas de suas afecções e suas experiências no trabalho em saúde ${ }^{30}$.

Além do diário cartográfico, a caixa de afecçôes ${ }^{31}$ foi uma das ferramentas utilizadas no processo formativo, sendo um lugar de produção de encontros, não com pessoas, mas com objetos e símbolos, produzindo deslocamentos no nosso corpo, do campo racional para o sensível, no qual as afetaçôes, ou seja, aquilo que nos afeta, trazem possibilidades de narrativas e aprendizados.

A caixa de afecções se propôs, a partir do sensível, ser uma caixa de ferramentas com um conjunto de saberes e tecnologias que se dispóe para a ação de produção dos atos de saúde, ou ainda como uma caixa-valise, como nos apresenta Marcel Duchamp, onde os objetos são recolhidos e trazidos como uma memória viva dos afetos produzidos nos territórios. Seja uma poesia, uma música, um encontro, um acontecimento qualquer que dispare um processo de EP e que traga possibilidades de narrativas diversas para o diário cartográfico ${ }^{31}$.

Essas ferramentas contribuem para refletirmos sobre o modelo hegemônico de formação centrado no saber já estruturado, testado e validado e que buscamos por (g) Regimes de verdade: discursos que funcionam como verdade, regras de enunciação da verdade com ligação circular com o poder, que, por sua vez, produz verdade e a sustenta, sendo que tal verdade produz efeitos de poder ${ }^{2}$.

(h) Vídeo institucional: Caixa de Afecções. Direção: Flávio Carnielli. https://www.youtube $\mathrm{com} /$ watch?v=oTKR3FB9vTg 
meio da informação, não valorizando a experiência na construção do conhecimento. Experiência é aqui entendida como "algo que se experimenta, algo que se prova, que vem do encontro e não aquele sujeito mais experiente passando ensinamentos para o menos experiente" 32 .

Nesse sentido, Bondia afirma que "a ciência moderna desconfia da experiência" 32 e valoriza o experimento, porque ele traz, em si, um certo grau de incerteza que o positivismo científico não admite.

Se o experimento é preditível e previsível, a experiência tem sempre uma dimensão de incerteza que não pode ser reduzida. Além disso, posto que não se pode antecipar o resultado, a experiência não é o caminho até um objetivo previsto, até uma meta que se conhece de antemão, mas é uma abertura para o desconhecido, para o que não se pode antecipar, nem "prever", nem "predizer" ${ }^{2}$.

Trazendo essa questão para o mundo do trabalho em saúde, podemos perceber que os espaços de intercessão entre usuários, trabalhadores e gestores produzem acontecimentos e experiências. Entretanto, o excesso de trabalho, o mecanicismo e a visão capitalista de saúde na lógica de consumista de produtos e serviços de saúde fazem com que o trabalho em saúde venha se afastando desse lugar de experimentar a potência dos encontros e assim produzir conhecimentos.

Se a experiência não é o que acontece, mas o que nos acontece, duas pessoas, ainda que enfrentem o mesmo acontecimento, não fazem a mesma experiência. O acontecimento é comum, mas a experiência é para cada qual sua, singular e de alguma maneira impossível de ser repetida ${ }^{32}$.

O saber da experiência é um saber que não pode separar-se do indivíduo concreto em quem encarna. Não está, como o conhecimento científico, fora de nós, mas somente tem sentido no modo como configura uma personalidade, um caráter, uma sensibilidade ou, em definitivo, uma forma humana singular de estar no mundo, que é por sua vez uma ética (um modo de conduzir-se) e uma estética (um estilo) ${ }^{32}$.

Uma outra aposta da EPS em Movimento é o reconhecimento e cooperação. Reconhecer significa enxergar o outro como sujeito produtor de conhecimentos a partir de suas experiências.

Em geral, as narrativas que predominam são as de que os trabalhadores não sabem, não entendem, sendo necessário capacitá-los. Por isso, os mecanismos de indução, sejam eles de premiação ou de punição, são muito comuns quando se trata de "política de recursos humanos".

Uma política de reconhecimento traz o conceito de alteridade ${ }^{(i)}$, que é produtor de tensôes no que se refere aos mecanismos de indução estabelecidos em algumas políticas. Sem querer polarizar o debate, a percepção inicial é a de que essas duas dimensões - "indução" e "reconhecimento e cooperação" - podem transitar mais ou menos intensamente nos espaços gestores e no mundo do trabalho macro e micropolíticos, interferindo, assim, nas políticas de saúde e de formação. (i) Alteridade significa reconhecer o outro como diferente, mas ter a capacidade de se colocar no lugar do outro, em uma relação baseada no diálogo e valorização das diferenças existentes. 
A política de EPS, desde a sua criação até o transcorrer de seus processos de mudança, e a recente experiência da EPS em Movimento contribuem para uma melhor compreensão desse tema do reconhecimento e da cooperação, que vai além do aspecto formativo propriamente dito, podendo ser perceptível, em maior ou menor escala, na conformação das políticas de saúde.

A política de EP se propóe a uma aprendizagem voltada para o trabalho, compreendendo que o trabalhador tanto sofre interferências como influencia esses processos produtivos, seja por interesses privativos ou para atender necessidades de saúde. Diferente de ser "um fora” ou um externo ao trabalho, o trabalhador é parte constitutiva dele, disputando protagonismo na elaboração de políticas públicas ${ }^{33}$.

A aposta pautada no reconhecimento e cooperação, seja no âmbito de uma formação ou em uma política de saúde, requer uma mudança de olhar, na qual se reconheça que todos sabem, todos governam, todos podem; na qual aprendemos uns com os outros por meio das experiências de cada um, que muitas vezes passam despercebidas ou invisíveis aos olhares governamentais. É possibilitar novas formas de produção que geram potência de vida e de existência no mundo do trabalho, pautadas na cooperação entre todos que fazem acontecer as políticas de saúde.

É dar visibilidade e dizibilidade a essa rede viva que já existe nos territórios físicos, subjetivos e existenciais: uma rede-rizoma ${ }^{4}$, sem hierarquias e baseada na produção de conhecimento a partir das experiências, nas quais as conexôes são definidas partindo de qualquer ponto dessa rede, seja um serviço de saúde, uma secretaria de saúde, uma microárea territorial, entre outros. A interdependência, o diálogo, a rede aberta, a troca de experiências e a EP acontecendo o tempo todo, a cada momento, a partir do reconhecimento de práticas e da cooperação entre as pessoas.

\section{Conclusão}

Embora o tema da EPS não pretenda se esgotar aqui, observa-se que ele tem muito a contribuir com as reflexões que estamos propondo sobre a construção das políticas de saúde no Brasil.

Partindo do pressuposto de que as políticas públicas são o resultado de um conjunto de açóes produzidas nos territórios, pode-se considerar a questão da materialização dessas políticas por parte dos trabalhadores no encontro com os usuários e com a gestão. A autonomia com que trabalhadores e usuários têm produzido os seus percursos, muitas vezes, fica fora do radar dos gestores que acham que estão controlando o trabalho apenas por planilhas gerenciais e sistemas de informação. Até que ponto então estamos construindo pertencimento, por parte dos usuários e trabalhadores, com essas políticas e com a defesa do SUS, que se encontra ameaçado?

O que passa invisível no radar do gestor está dito nas narrativas desses trabalhadores, gestores locais e usuários, em vários espaços formais e informais dos serviços de saúde e nas comunidades como formas de resistir e existir no mundo do trabalho. 
É a rede viva que opera no sistema de saúde que nos possibilita enxergar os aspectos micropolíticos do trabalho que interferem nas políticas de saúde implementadas. Como aprender então a "transver esse mundo", como nos convida o poeta Manuel de Barros $^{34}$, e permitir a emergência dessas multiplicidades?

Valorizar o encontro, as escutas e as formas com que os trabalhadores e usuários inventam os seus modos de produção pode ser um caminho, além de ir ao encontro dessas experiências, não com o objetivo de fiscalizá-las ou apropriarse instrumentalmente delas, mas buscando rastrear a potência de cada uma delas. Reconhecer que todos, com base em suas histórias e experiências de vida, inventam soluções para responder a questóes complexas do cotidiano e que todos aprendemos uns com os outros, em um aprendizado contínuo, fundamentado na vivência e no encontro, e não apenas na transmissão do saber.

Sair de uma posição de suposto saber para considerar, como defende Merhy ${ }^{29}$, que no trabalho em saúde se aprende e se ensina nos atos de cuidado e também de descuido. Reconhecer, como afirma o autor, que todos os trabalhadores e gestores do SUS, em suas práticas cotidianas, fazem ou estão em educação permanente - seja no café, no corredor de uma unidade de saúde ou dentro do consultório, independentemente de qual seja a sua intencionalidade - e que, portanto, também governam as políticas de saúde.

Sendo assim, a visão de política pública deixa de ser uma ação apenas do Estado e passa a ser um acontecimento, produzido no cotidiano a partir das múltiplas interaçóes rizomáticas ${ }^{8}$, que mobilizam os indivíduos. Uma política construída sem reconhecer esses movimentos pode produzir desresponsabilização e baixa implicação dos trabalhadores e gestores.

Mesmo que a formulação de uma política venha a se transformar em um ato normativo, as diversas formas como ela é concebida e implementada, sempre com múltiplas conexóes e acontecimentos produzidos no cotidiano da micropolítica, a coloca em um plano de imanência ${ }^{2}$, como defende Foucault, e como algo que emana de todos, e não apenas de um conjunto de atores que irão definir o que é melhor para todos. Reconhecer esses movimentos e a potência que eles trazem e considerá-los nas apostas políticas são possibilidades que essa reflexão traz para a construção de políticas de saúde no SUS.

\section{Contribuições dos autores}

Monica Sampaio de Carvalho foi responsável pela concepção e delineamento do trabalho e participou ativamente de todas as etapas de elaboração do manuscrito; Maria Fátima de Sousa e Emersom Elias Merhy contribuíram, respectivamente, como orientadora e coorientador da tese de doutorado de Monica Sampaio de Carvalho, participando da discussão dos resultados, revisão crítica do conteúdo e aprovação da versão final do manuscrito.

\section{Direitos autorais}

Este artigo está licenciado sob a Licença Internacional Creative Commons 4.0, tipo BY (https://creativecommons.org/licenses/by/4.0/deed.pt_BR). 


\section{Referências}

1. Brasil. Ministério da Saúde. Portaria no 2.203, de 5 de Novembro de 1996. Norma operacional básica - NOB - 1/96. Diário Oficial da União. 6 Nov 1996.

2. Foucault M. Microfísica do poder. São Paulo: Graal; 1996.

3. Foucault M. O nascimento da clínica. Machado R, tradutor. 5a ed. Rio de Janeiro: Forense Universitária; 1998.

4. Deleuze G, Guatarri F. Mil platôs: capitalismo e esquizofrenia. Guerra Neto A, Costa CP, tradutor. Rio de Janeiro: Ediçóes 34; 1995. v. 1.

5. Merhy E. Saúde: a cartografia do trabalho vivo. São Paulo: Hucitec; 2002.

6. Feuerwerker LCM. Micropolítica e saúde: produção do cuidado, gestão e formação. Porto Alegre: Rede Unida; 2014.

7. Guatarri F, Rolnik S. Cartografias do desejo. 4a ed. Petrópolis: Editora Vozes; 1986.

8. Rolnik S. Cartografia sentimental: transformações contemporâneas do desejo. Porto Alegre: Editora UFRGS; 2007. p. 23-70.

9. Furter P. Educação permanente e desenvolvimento cultural. Petrópolis: Vozes; 1975.

10. Organização das Nações Unidas para a Educação, a Ciência e a Cultura. Educação: um tesouro a descobrir. Relatório para a Unesco da Comissão Internacional sobre Educação para o século XXI. Brasília: Unesco; 1998.

11. Freire P. Pedagogia do oprimido. 17a ed. Rio de Janeiro: Paz e Terra; 1987.

12. Ribeiro D. O processo civilizatório. Estudos de antropologia da civilização: etapas da evolução sociocultural. São Paulo: Companhia das Letras, Clube Folha; 2000.

13. Fernandes F. O desafio educacional. São Paulo: Editora Cortez; 1989.

14. Organização Pan-Americana de Saúde. Educación permanente de personal de salud en la región de las américas. Washington: Opas; 1988. Fascículo I: Propuesta de reorientación. Fundamentos. (Serie de desarrollo de recursos humanos, o 78).

15. Ceccim RB. Onde se lê recursos humanos da saúde, leia-se coletivos organizados de produção da saúde: desafios para a educação. In: Pinheiro R, Mattos R, organizadores. Construção social da demanda: direito à saúde, trabalho em equipe, participação e espaços públicos. Rio de Janeiro: Abrasco; 2005.

16. Brasil. Ministério da Saúde. Resolução no 335, de 27 de Novembro de 2003. Afirma a aprovação da "Política Nacional de Formação e Desenvolvimento para o SUS: Caminhos para a Educação Permanente em Saúde”. Diário Oficial da União. 5 Fev 2004.

17. Brasil. Ministério da Saúde. Portaria no 198/GM/MS, de 13 de Fevereiro de 2004. Institui a Política Nacional de Educação Permanente na Saúde como estratégia do SUS para formação e desenvolvimento de trabalhadores para o setor e dá outras providências. Brasília: Ministério da Saúde; 2004.

18. Ceccim RB, Feuerwerker LCM. O quadrilátero da formação para a área da saúde: ensino, gestão, atenção e controle social. Physis. 2004; 14(1):41-65.

19. Brasil. Ministério da Saúde. Secretaria de Gestão do Trabalho e da Educação na Saúde. Departamento de Gestão da Educação na Saúde. Curso de Formação de facilitadores de educação permanente em saúde: unidade de aprendizagem - análise do contexto da gestão e das práticas de saúde. Rio de Janeiro: Ministério da Saúde, Fiocruz; 2005. 
20. Fundação Oswaldo Cruz. Relatório final do curso de especialização em ativação de processos de mudança. Brasília, Rio de Janeiro: Ministério da Saúde, Fiocruz; 2007.

21. Ceccim RB, Ferla A. Educação e saúde: ensino e cidadania como travessia de fronteiras. Trab Educ Saude. 2008; 6(3):443-56. doi: http://dx.doi.org/10.1590/ S1981-77462008000300003.

22. Brasil. Ministério da Saúde. Edital MCT/CNPQ/MS-SCTIE-DECIT no 23/2006, Programa Especial de Cooperação com o Ministério da Saúde. Avaliação das Experiências de Educação Permanente em Saúde desencadeadas a partir da formação a distância de tutores e facilitadores em todas as regióes do Brasil. Brasília: Ministério da Saúde; 2006.

23. Brasil. Ministério da Saúde. Portaria no 1.996, de 20 de Agosto de 2007. Dispóe sobre as diretrizes para a implementação da Política Nacional de Educação Permanente em Saúde. Brasília: Ministério da Saúde; 2007.

24. Cavalcanti FOP. Educação permanente em saúde, entre o passado e o futuro [tese] Rio de Janeiro: Centro Biomédico, Instituto de Medicina Social, Universidade do Estado do Rio de Janeiro; 2015.

25. Plataforma OTICS. Educação permanente em movimento [Internet]. 2018 [citado 1 Dez 2018]. Disponível em: http://eps.otics.org

26. Deleuze G. ¿Que és un dispositivo? In: Foucault M. Filósofo. Barcelona: Gedisa; 1990. p. 155-61.

27. Merhy E, Magalhães Júnior HM, Rimoli J, Franco TB, Bueno WS. O trabalho em saúde: olhando e experimentando o SUS no cotidiano. São Paulo: Hucitec; 2003.

28. Spinoza B. Ética demonstrada à maneira dos geômetras. São Paulo: Martin Claret; 2005. p. 195-367.

29. Trindade R. Bento de Espinosa [Internet]. 2018 [citado 1 Dez 2018]. Disponível em: https://razaoinadequada.com/filosofosessenciais/espinosa.

30. Observatório de Tecnologias em Informação e Comunicação em Sistemas e Serviços de Saúde - OTICS. Educação Permente em Saúde em Movimento. Caixa de afecçóes [Internet]. Brasil: OTICS; 2019 [citado 4 Fev 2019]. Disponível em: http://eps.otics. org/material/entrada-experimentacoes/caixa-de-afeccoes

31. Observatório de Tecnologias em Informação e Comunicação em Sistemas e Serviços de Saúde - OTICS. Educação Permente em Saúde em Movimento. Diário Cartográfico [Internet]. Brasil: OTICS; 2019 [citado 4 Fev 2019]. Disponível em: http://eps.otics.org/material/entrada-apresentacao/apresentacao-diario-cartografico

32. Bondia J. Notas sobre a experiência e o saber de experiência. Rev Bras Educ. 2002; (19):20-8.

33. Merhy E. Educação permanente em saúde em movimento: uma política de reconhecimento e cooperação, construindo encontros no cotidiano das práticas de saúde. Porto Alegre; 2013. (Texto escrito como contribuição para o DEGES/SGTES/ MS).

34. Barros M. Livro sobre nada. 3a ed. Rio de Janeiro, São Paulo: Editora Record; 1996. As liçốes de R. Q.; p. 75. 
This article discusses the program "Continuing Health Education in Movement" (EPS em Movimento) implemented by the Ministry of Health's Department of Health Education Management (DEGES, acronym in Portuguese) in partnership with academic institutions and the workers and administrators of the Brazilian National Health System (SUS). Its main aim is to give visibility to EPS experience resulting from the affects and encounters. The authors aim to map and understand this experience, its innovative nature, and connection with the ways in which health policies for SUS are being formulated and implemented, including the Continuing Education in Health Policy established in Brazil since 2003.

Keyword: Health policy. Continuing education. Encounter.

El objetivo de este artículo es discutir la formación en Educación Permanente en Salud (EPS), denominada EPS en Movimiento y realizada en 2012 por el Departamento de Gestión de la Educación en Salud (DEGES) de la Secretaría de Gestión del Trabajo y de la Educación en Salud (SGTES) del Ministerio de Salud (MS) de Brasil en alianza con instituciones de enseñanza, trabajadores y gestores del Sistema Brasileño de Salud (SUS), y cuya apuesta principal fue la de dar visibilidad a la experiencia de EPS provenientes de las afecciones y de los encuentros. Los autores pretenden cartografiar y comprender esa experiencia, su carácter innovador y conexión con los modos como las políticas de salud para el SUS se formulan e implementan, incluyendo la Política de Educación Permanente en Salud instituida en Brasil desde 2003.

Palabras clave: Políticas de salud. Educación permanente. Encuentro. 